\title{
Immersive Planetarium Visualizations For Teaching Solar System Moon Concepts To Undergraduates
}

\author{
Ka Chun Yu, Denver Museum of Nature \& Science, USA \\ Kamran Sahami, Metropolitan State University of Denver, USA \\ Grant Denn, Metropolitan State University of Denver, USA \\ Victoria Sahami, Metropolitan State University of Denver, USA \\ Larry C. Sessions, Metropolitan State University of Denver, USA
}

\begin{abstract}
Digital video fulldome has long been heralded as a revolutionary educational technology; yet the discipline-based astronomy education research literature showing planetarium effectiveness has been sparse. In order to help understand to what extent immersion impacts learning and the effect of the "narrative journey" model of presentation, we conducted a pre- and post-test effectiveness study of lectures on moon systems in the Solar System presented to 781 college undergraduates under immersive and non-immersive treatment conditions. Although all students showed some learning gains immediately after instruction, those who saw presentations in an immersive fulldome planetarium showed the greatest retention, compared to control classes that witnessed the same lecture and visuals on a flat screen in their regular classroom, and students that saw no interactive visuals. Because the same instructors, presentation visuals, and instructional outline were used for both the classroom and dome instruction using the virtual environment, the results suggest that the large display and wide field-of-view, two elements unique to the dome, resulted in greater attention, and were primarily responsible for the greater gains.
\end{abstract}

Keywords: Astronomy Education; Computer Simulation; Planetarium; Undergraduate Education

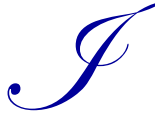

mmersive virtual environments (IVEs) have been embraced for a variety of uses, including training, education, psychological therapy, data visualization, and research (Bailenson, Yee, Blascovich, Beall, Lundblad, \& Jin, 2008; Dede, Salzman, Loftin, \& Sprague, 1999; Loomis, Blascovich, \& Beall, 1999; Durlach \& Mavor, 1995; Raja, Bowman, Lucas, \& North, 2004). One popular form of IVE that has become common for education and entertainment recently are the digital fulldome theaters (Lantz, 2011). Having evolved from planetariums, these venues are typically large, allowing up to hundreds of viewers to have a common immersive visual experience via digital projection onto the interior of a hemispherical dome. Like their traditional virtual reality counterparts, fulldome IVEs allow audiences to gain direct experience about a place or phenomenon that would otherwise be difficult or impossible to observe in real life (Dede, 2000).

Although nearly 1400 fulldome theaters, mostly in informal and formal science education settings, have opened worldwide (Lochness Productions, 2016), little empirical research has been done to study this medium (Schnall, Hedge, \& Weaver 2012; Slater, Ratcliff, \& Tatge, 2017). Because of their planetarium heritage, many fulldome theaters are equipped with interactive real-time software for generating an IVE of the physical universe (Emmart, 2005). Most research involving them is associated with space sciences. Yu (2005) has highlighted the potential benefits of fulldome for astronomy education: revealing three-dimensional (3D) spatial relationships, demonstrating accurate motions and lighting of astronomical bodies, and placing the viewer in multiple frames of reference. Studies in discipline-based astronomy education research has typically shown how fulldome theaters benefit topics that involve understanding of spatial relationships, such as motions of celestial bodies (Plummer, Kocareli, \& Slagle, 2014), phases of the Moon (Chastenay, 2015), and Earth's seasons (Yu, Sahami, Sahami, \& Sessions, 2015). Yet there are other aspects of the fulldome theater experience that have not been well studied in prior research. We focus on the role of visual immersion in this study. 


\section{Immersion in Fulldome}

Immersion has been defined by the degree to which the senses are dominated by a computer-mediated environment (Arsenault, 2005; Fiore, Harrison, Hughes, \& Rutström, 2009; Nunez, 2004). Following Slater (2003), we define immersion from an IVE to be the objectively quantifiable elements of a high-fidelity mediated experience. (This is separate from presence, which is an individual's perceptual response to the immersive environment, and can vary from one person to the next for the same mediated experience.) A wide field-of-view (FOV) and a physically large display are two measurable factors of immersion that have been demonstrated to have positive effects in previous research on user performance. The FOV impacts the ability of a user to acquire spatial information. Content seen in the periphery of the retina attracts greater attention than content in the central foveal region of vision (Livingstone \& Hubel, 1988). Larger FOVs are associated with faster search times for objects, with more efficient combination of eye and head motions (Venturino \& Wells, 1990). By contrast, smaller FOVs can be a detriment to navigation performance and maneuvering through an IVE. The loss of peripheral vision from a restricted FOV leads to decreased ability to judge headings and distances, and maintain situational awareness, which can lead to reduced confidence (Toet, Jansen, \& Delleman, 2007). Wide FOV and high resolution displays result in better navigation and wayfinding (Ni, Bowman, \& Chen, 2006). Physically large displays can impact viewers independently of FOV. Larger imagery lead to greater attention, arousal, and excitement in viewers (Lombard., Reich, Grabe, Bracken, \& Ditton, 2000; Reeves, Detenber, \& Steuer, 1999). Even when the visual content has the same angular size, users of large displays do better on tasks involving spatial orientation, navigation, map formation, and memory (Tan, Gergle, Scupelli, \& Pausch, 2006). This may be due to viewers switching to more efficient egocentric strategies when performing a task, where they imagine themselves inside the environment and rotating their bodies to match angles (versus an exocentric strategy where viewers are outside of the environment, and imagine objects rotating independently of their bodies).

Although fulldome hemispherical displays are very visually immersive, they are unlike other virtual reality technologies because they lack (or have limited) head-tracking, audience interaction, and stereoscopic projection. When we refer to immersion from here on, it will be with respect to only the FOV and large display surface of the fulldome display, and not any other factors, which do not play a role in our study. Immersion here is dominated only by the artificially-generated environment filling the visual field of the audience, overpowering other visual stimuli, and leading the viewer to focus entirely on the virtual imagery (Ermi \& Mayra, 2005).

The effect of immersion in fulldome has been investigated in two recent evaluations. The 35 minute long Tales of the Maya Skies (Wong, 2009) was shown to adult audiences in different venues with varying levels of immersion (a fulldome theater, a giant screen theater, a large TV set). Surveys from 233 participants revealed that the fulldome experience was more effective than the less immersive shows at conveying scientific information and inspiring further learning. Not only did fulldome audience members have higher post-test knowledge scores, but they viewed the film as more immersive, and perceived the program and visuals to be the most positive and least negative (Heimlich, Sickler, Yocco, \& Storksdieck, 2010). The 24 minute film We Choose Space! (Sumners, 2012) was shown to 574 middle and high school students inside immersive domes, as well as on flat desktop computer screens. Audiences at the immersive presentation had greater learning gains than those seeing the flat-screen version; six weeks after the treatment, the gains increased slightly for the fulldome cohort, but shrank for the second group (Zimmerman, Spillane, Reiff, \& Sumners, 2014). Although these two studies compared immersive and non-immersive treatments, neither tried to explain why the immersion was effective.

Immersion may also impact the cognitive load of an audience member in a fulldome theater. In our study of undergraduate students taking an introductory astronomy course, Yu and colleagues (2015) argue that fulldome visuals are better than non-immersive visuals for learning about Earth's seasons because spatial information of celestial bodies can be experienced egocentrically, which frees up cognitive resources for constructing the astronomical mental model. In Jacobson's (2010) study, 11-14 year old students played an educational computer game taking them on a tour of an Egyptian temple. Compared to those who saw a desktop presentation, students who completed the immersive tour were able to create video guides of their experience with more factual knowledge and conceptual explanations. This may be due to a more efficient examination of the virtual environment in the immersive case, which also reduces the cognitive load. In both these cases, students were able to organize and structure information more effectively in the immersive experience than their counterparts who saw non-immersive visuals. 


\section{The Narrative Journey}

Presentations in fulldome theaters tend to follow that of the "narrative journey" (Wyatt, 2005), where audiences are taken on virtual tours with few cuts or edits, making the visual experience nearly seamless. The audience experiences point-of-view shots from the virtual camera that make them feel that they are literally moving through space, putting them in the action, instead of being passive observers (Shedd, 2003). Camera motions such as pans and tracks are slowed down in fulldome live presentations and films, because faster movements can otherwise lead to motion sickness in viewers (Wyatt, 2005). Cuts cannot happen quickly in succession, because viewers are jarringly transported into a new scene with each cut. Instead viewers are given time to adjust to their surroundings to avoid confusion. At the same time, the continuous journey through multiple scales allow viewers to reflect on those size relationships relative to the human scale, while also linking physical processes and phenomena at the different scales (Wyatt, 2014).

Many fulldome planetarium astronomy presentations involve a live presenter controlling the content via the IVE software, and delivering tours of the known universe via visualizations of astrophysical datasets to audiences (Wyatt, 2005). Because the scale of the universe spans multiple orders of magnitude, all astronomical visualization software running in planetariums are able to provide trans-scalar navigation via seamless, continuous flightpaths. It is possible to reproduce the centerpiece camera zoom from the Powers of Ten film (Eames \& Eames, 1977), but with the added ability to steer to different destinations (Emmart, 2005). Hence the format of these seamless presentations take on by default the form of a narrative journey. Most films produced for fulldome use the narrative journey model, and so do the virtual flights through planetary moon systems designed for this study.

\section{Instruction on Planetary Moons}

Understanding the cycles of phases and celestial motions of Earth's Moon is part of the guidelines for K-12 science instruction as recommended by the National Research Council's National Science Education Standards (1996) and the American Association for the Advancement of Science's Project 2061: Benchmarks for Science Literacy (1986). A considerable body of educational research exists on the teaching of these topics, including alternative conceptions and understanding of the Earth-Moon-Sun system (Jones, Lynch, \& Reesink, 1987; Stahly, Krockover, \& Shepardson, 1999), phases of the Moon (Barnett and Moran, 2002; Baxter, 1989; Kavanagh, Agan, \& Sneider, 2005; Schoon, 1988), and lunar eclipses (Kavanagh, Agan, \& Sneider, 2005; Trundle, Atwood, \& Christopher, 2002). Such alternative conceptions are deeply engrained knowledge that the learner has before instruction, which can be very difficult to correct (Brewer, 2008; Wandersee, Mintzes, \& Novak, 1994). Studies have also focused on various treatments to improve instruction and understanding of these concepts using physical models (Callison \& Wright, 1993), semester-long projects and activities (Barnett and Moran, 2002), recording observations through lunar journals (Abell, Martini, \& George, 2001; Trundle, Atwood, \& Christopher, 2007), kinesthetic activities (Plummer, 2014), virtual model building (Barab, Hay, Barnett, \& Keating, 2000), and visualizations from virtual planetarium software (Bell \& Trundle, 2008).

Compared with Earth's Moon, we find that no comparable work investigating student understanding of other moons in the Solar System exists. Comins (2007) has compiled astronomy-related preconceptions from undergraduate students related to other moons. However many appear to be merely factual errors which could be corrected via traditional lectures, instead of alternative conceptions that are difficult to dislodge. These erroneous ideas include the beliefs that other moons are similar to Earth's Moon in size, shape, color, composition, and lack of atmosphere; and the number of moons in the Solar System is believed to be far fewer than the actual quantity.

The American Astronomical Society's Goals for Astro 101 recommends thematic goals in undergraduate astronomy courses, including the key objective for undergraduate students to gain a cosmic perspective: "a broad understanding of the nature, scope, and evolution of the Universe, and where the Earth and Solar System fit in" (Partridge \& Greenstein, 2004). The AAS Goals recommends goals for not just instructional content, but also skills, values, and attitudes about science that students should gain from their study. As a result, there is not a recommended "irreducible core of essential knowledge" that must be taught. Instead college instructors should have the freedom to decide on the specifics of that content knowledge to match the educational themes. 
Given the flexibility of introductory undergraduate astronomy curriculum, we chose moons around other planets of the Solar System as a topic for student assessment in this study. All IVE software available for fulldome planetariums can depict the number, appearance, and orbital motions of moons around the planets, while their dynamical accuracy can be used to simulate phenomena like tidal locking and orbital resonance. Undergraduate audiences can be taken on virtual tours to the moons and planets embedded inside the virtual Solar System using the narrative journey model.

\section{Theoretical Framework for this Study}

With university-level teaching, students are expected to gain access to specialist knowledge, and to be familiar with the type of discourse of terminology specific to a field of study. University students take courses within a particular discipline to learn how to participate using the specialist discourse that is found within that community (Northedge, 2002). This is often not straightforward, since disciplinary specialists may be unable to recognize that novices do not have the same level of discernment that experts do about their discipline (Bransford, Brown, \& Cocking, 2000). Understanding the frames of reference of a discourse cannot be done simply through learning definitions, since students will not have the context to make sense of and internalize the definitions. Instead meaning making will come only through exposure to an intermediate discourse that is familiar for the student. To help learners who do not have the appropriate frame of reference to understand the specialist discourse, it is the job of the instructor to re-frame meanings, and guide learners into the specialist domain of understanding, until they can make meaning on their own (Northedge, 2002).

Disciplinary discernment in astronomy through the use of visualizations has been investigated by Eriksson and colleagues (2014b). They define disciplinary discernment as "noticing something, reflecting on it, and constructing meaning from a disciplinary perspective" (p. 170). They further construct a hierarchical "anatomy" of different levels of disciplinary discernment, from beginning to advanced levels of understanding. This ranges from simply recognizing or naming objects in an astronomical representation, to assigning disciplinary meaning to the object, to combining different elements of disciplinary knowledge to create a greater holistic understanding, to analyzing and critiquing the object representation. Eriksson and colleagues' proposed "anatomy of disciplinary discernment" provides a framework by which instructors can create learning environments that allow learners to cross into increasingly advanced levels of discernment. The use of astronomical visualizations combined with a guided "tour" from the instructor in this study follows their model. In our case, the instruction is a purposefully constructed scaffold to help students attain disciplinary discernment about various principles concerning moons in the Solar System. In the simplest case, this may involve identifying and naming other planetary moons in the Solar System. More sophisticated is to combine different disciplinary principles in astronomy (e.g., moon-like bodies can orbit the Sun independently of the planets; their orbits can take them close to planets; the gravity of planets can alter the trajectories of orbiting bodies; these secondary bodies can end up in orbit around a planet they were not orbiting before; these other bodies can impact or accrete onto the planet; impacts can eject material back into space) into holistic understanding of the various scenarios that have been proposed for the formation of planetary moons.

Although the empirical research surrounding fulldome IVEs is sparse, there are enough similarities between them and other types of IVEs that a fulldome experience is suspected to have impacts on visual perception, attention, and memory (Schnall, Hedge, \& Weaver, 2012). This has led Fraser and colleagues (2012) to take Kolb's (1984) constructivist experiential learning model adapted for 3D and IVEs (de Freitas \& Neumann, 2009), and propose that heightened immersion from the large screen experiences can lead to better understanding of scientific concepts by viewers. This is supported by research showing that 3D VE representations can lead to greater understanding of spatial relationships (e.g., Angelov, Smieja, \& Styczunski, 2007; Barnea \& Dori, 1999; Eriksson, Linder, Airey, \& Redfors, 2014a; Keating, Barnett, Barab, \& Hay, 2002); and how immersive environments may lead to increased user interest, engagement and motivation for learning (Korakakis, Pavlatou, Palyvos, \& Spyrellis, 2009). Based on this prior work, we propose to investigate the research question, to what extent does the immersion of the fulldome environment impact the amount of learning that occurs? 


\section{METHOD}

Undergraduate students enrolled in introductory astronomy survey classes at a large, urban, masters-granting university during the fall 2005 to spring 2010 semesters were subjects in this study. The project had an initial development phase where results from prior-to-instruction, semi-structured oral interviews with 110 students in the first two semesters guided the creation of new lecture outlines to directly address common student alternative conceptions. During these interviews, students were asked the following questions about the topic of moons (natural satellites) of our Solar System:

- Can you tell me what a moon is?

- Earth has a Moon; do the other planets have moons as well?

- How many moons do you think there are in the solar system? What else do you know about them?

Analysis and categorization of student ideas in the transcribed interviews done independently by two of the authors confirm some of Comins' (2007) findings: morphological errors where moons were confused with other objects like stars and asteroids; mistaken ideas about the absence or presence of moons around each planet; and the belief that moons originate only as captured asteroids, instead of entertaining other scenarios like accretion or condensation after a giant impact. However like many topics in astronomy, these mistaken conceptions are not likely to be the result of any misunderstanding that has been constructed through direct experience. Most college-level astronomy topics are presented to students for the first time in their introductory class, so it is not expected students would harbor deepseated misconceptions based on coherent mental models of phenomena they have experienced over a lifetime (Slater, 2014). Thus the detailed lecture outlines on Solar System moons developed by the authors were designed only to address factual preconceptions that students may have.

\section{Instruction with Visualizations in the Planetarium and Classroom}

Students were not randomly assigned to the different treatments. Instead the seventeen classes taking part in the quasiexperimental study were divided into three groups. Group I (GI) classes saw no visualizations and were used to establish a baseline for traditional classroom instruction. Two treatment groups were exposed to instruction using visualizations projected onto a flat screen in the classroom (Group II, or GII) or via immersive versions projected in the Denver Museum of Nature \& Science's fulldome Gates Planetarium (Group III, or GIII). To prevent students from preferentially pre-registering for a particular treatment, the experimental group assignment was not announced until the first day of the class, which was also when students were offered the opportunity to participate in the study. The two instructors (authors V. Sahami and L. Sessions) taught roughly equal numbers of classes within each Group. All of the classes used the same textbook, and were presented with the same lectures for the topic of planetary moons, following the same outline, and at the same pace. To avoid confounding the impact of the visualizations, no other animations were shown in any of the classes. GI students were exposed to classroom lectures supplemented by a PowerPoint presentation containing still pictures and text about Solar System moons and the planets they orbit. There were 153, 239, and 389 participating students in GI, GII, and GIII, respectively, for a total of 781. More details about the classroom and planetarium environments, the level of student participation, and the logistics of GIII class visits to the planetarium can be found in $\mathrm{Yu}$ and colleagues (2015).

For GII and GIII, the Uniview ${ }^{\mathrm{TM}}$ planetarium software developed by the company SCISS AB was used to generate a virtual tour of the Solar System. In addition to the instructor, a skilled navigator was present either in the classroom or in the planetarium to pilot the software to create a virtual flight that followed the lecture outline in real-time. The classes undergoing the experimental treatment would see realistic visuals of moons and planets (based on imagery of their surfaces captured by Earth-bound telescopes and visiting spacecraft) in a flat-screen projection at the front of their class (GII), or via immersive visuals surrounding them in the digital planetarium (GIII). The tour was presented as a seamless narrative journey through the simulation, from one celestial body to the next, with no edits or "cuts." The lecture started off by demonstrating that Earth's Moon keeps the same face turned toward our home planet during its entire orbit (tidal locking). The tour next took the audience to Mercury and Venus, where the instructor pointed out that they have no natural satellites. Mars' two small satellites were identified as likely captured asteroids, while their tidal locking was also demonstrated. The satellites of Jupiter, Saturn, Uranus, and Neptune were explored in turn. For 
each of them, the orbital paths were shown to highlight the large number of moons around each of the outer planets, as well as the fact that most do not orbit parallel to the planet's equator (i.e., they are non-co-planar). Select large satellites of the large planets were chosen for close flybys, for which the instructors gave specific information about the worlds that the students were virtually visiting. With Jupiter's four large "Galilean" moons, the software was used to show not only their tidal locking, but also the idea of orbital resonances between the inner three moons (e.g., Yoder, 1979). This last demonstration was the only exception to the continuous narrative journey model: the camera-and audience - were transported via "camera cuts" to different simulation times and camera angles to show the resonance set-up for each moon.

\section{Curriculum Assessments}

The authors (all of whom have extensive teaching and research experience in astronomy) developed a set of multiple choice questions for use in weekly student assessments. ${ }^{1}$ The questions were inspired in part by the factually erroneous ideas held by students discovered in the interviews: confusion about morphology of moons (e.g., that they are the same as stars, comets, and asteroids); the total number of moons in the Solar System; the number and identity of moons around the various planets; and the origins of moons (which can include gravitational capture, condensation, and giant impact of parent planet). The weekly exams contained questions for all topics covered in the 15 week course. The Week 3 assessment also contained five additional pre-instruction questions on planetary moons. Ten questions were used to gauge learning immediately after instruction, usually in Week 6 (although four classes had them in Week 5, and in one class, in Week 7). Four post-instruction questions were given 3-4 weeks later. The same pre-instruction, contemporaneous, and post-instruction questions were used for all of the classes (Appendix A). Kuder-Richardson 20 (KR20) analyses show a reliability of $0.38,0.49$, and 0.54 for respectively, the pre-instruction, contemporaneous, and post-instruction questions, which are good values for reliability for tests with such few questions. After grading, the assessment questions were not released to the students to prevent questions from being passed to students in different cohorts. (Students could request a meeting with an instructor to see and discuss test results.)

The three GI classes took place in fall 2006. Five GII and nine GIII classes were alternately taught from the fall 2007 through spring 2010 semesters. Results from all of the classes within each Group have been aggregated together for the analysis.

\section{RESULTS}

Our results include average pre-instruction, contemporaneous, and post-instruction assessment scores for the three different treatment groups (Table 1), and mean longitudinal gains determined by comparing the contemporaneous and pre-instruction (Cont-Pre), post-instruction and contemporaneous (Post-Cont), and the post- and pre-instruction (PostPre) assessments (Table 2). Since these are longitudinal gains, they include data only from those students who were present for all three assessments. Further analyses of these results can be found in Appendix B.

In Fig. 1, we plot results from Table 2, showing gains in effect sizes with $95 \%$ confidence interval levels between the Post-Pre, Cont-Pre, and Post-Cont assessment pairs, for the three different experimental Groups. All students regardless of which treatment group they were from had positive Cont-Pre gains, which show gains immediately after instruction. However, the Post-Cont differences were all losses, and the Post-Pre gains were close to zero except for students in GIII who had a moderate effect size $E S=0.371$. The large initial increase in GI's Cont scores, followed by the subsequent drop of the same magnitude in the Post scores, is difficult to explain. The control group consists of students from three classes in the fall 2006 semester, with the total 110 students a smaller sample compared to those undergoing the GII and GIII treatments. Thus the control classes could be outliers due to their small number. GII's Cont and Post scores also mirror a similar rise and fall (but with an effect size half that of GI), leading to little net gain when comparing post- versus pre-instruction scores. In summary, students in both the control Group I (with no

\footnotetext{
${ }^{1}$ Note that the instructors tried to give similar instruction regardless of which experimental group their class was assigned to. However since they also participated in the experimental design, we cannot guarantee that some subtle bias may have crept into their teaching if they were partial to one treatment over another.
} 
visualizations) and GII (who saw non-immersive visualizations in their classrooms) showed almost no retention by the time of the post-instruction assessment, while GIII students who visited the planetarium still held onto a modest gain.

Table 1. The mean score (M), number of students (n), standard error (SE), and 95\% confidence intervals (CI) in the pre-instruction, contemporaneous, and post-instruction assessments.

\begin{tabular}{|c|c|c|c|c|}
\hline & & \multicolumn{3}{|c|}{ Average Scores } \\
\hline & & Pre & Cont & Post \\
\hline \multirow{4}{*}{ Group I } & $M$ & $33.3 \%$ & $59.3 \%$ & $34.6 \%$ \\
\hline & $n$ & 110 & 110 & 93 \\
\hline & $S E$ & $2.7 \%$ & $2.3 \%$ & $2.0 \%$ \\
\hline & $95 \% C I$ & $4.5 \%$ & $4.6 \%$ & $4.0 \%$ \\
\hline \multirow{4}{*}{ Group II } & $M$ & $35.4 \%$ & $46.7 \%$ & $34.8 \%$ \\
\hline & $n$ & 183 & 209 & 192 \\
\hline & $S E$ & $1.7 \%$ & $1.7 \%$ & $1.8 \%$ \\
\hline & $95 \% C I$ & $3.4 \%$ & $3.4 \%$ & $3.6 \%$ \\
\hline \multirow{4}{*}{ Group III } & $M$ & $33.2 \%$ & $47.8 \%$ & $43.1 \%$ \\
\hline & $n$ & 322 & 320 & 267 \\
\hline & $S E$ & $1.4 \%$ & $1.4 \%$ & $1.4 \%$ \\
\hline & $95 \% C I$ & $2.7 \%$ & $2.7 \%$ & $2.9 \%$ \\
\hline
\end{tabular}

Table 2. The gain g (expressed in percentages and effect sizes), number of students (n), standard error (SE), and 95\% confidence intervals $(\mathrm{CI})$ of the difference in contemporaneous and pre-instruction scores, and post- and pre-instruction, and post-instruction and contemporaneous scores. The values in bold are plotted in Fig. 1.

\begin{tabular}{|c|c|c|c|c|c|c|c|}
\hline & \multicolumn{3}{|c|}{ Gains } & \multicolumn{3}{|c|}{ Effect Size } \\
\hline & & Cont-Pre & Post-Pre & Post - Cont & Cont-Pre & Post-Pre & Post - Cont \\
\hline \multirow{4}{*}{ Group I } & $g$ & $27.3 \%$ & $0.7 \%$ & $-23.9 \%$ & 1.14 & 0.03 & -1.078 \\
\hline & $n$ & 94 & 84 & 85 & 94 & 84 & 85 \\
\hline & $S E$ & $3.2 \%$ & $3.5 \%$ & $3.1 \%$ & 0.133 & 0.157 & 0.138 \\
\hline & $95 \% \mathrm{CI}$ & $6.3 \%$ & $6.9 \%$ & $6.1 \%$ & 0.264 & 0.313 & 0.274 \\
\hline \multirow{4}{*}{$\begin{array}{c}\text { Group } \\
\text { II }\end{array}$} & $g$ & $12.7 \%$ & $0.4 \%$ & $-11.9 \%$ & 0.527 & 0.019 & -0.535 \\
\hline & $n$ & 172 & 158 & 187 & 172 & 158 & 187 \\
\hline & $S E$ & $2.2 \%$ & $2.6 \%$ & $2.2 \%$ & 0.091 & 0.120 & 0.098 \\
\hline & $95 \% \mathrm{CI}$ & $4.3 \%$ & $5.2 \%$ & $4.3 \%$ & 0.180 & 0.236 & 0.193 \\
\hline \multirow{4}{*}{$\begin{array}{c}\text { Group } \\
\text { III }\end{array}$} & $g$ & $14.4 \%$ & $8.2 \%$ & $-6.2 \%$ & 0.599 & 0.371 & -0.277 \\
\hline & $n$ & 289 & 248 & 250 & 289 & 248 & 250 \\
\hline & $S E$ & $1.6 \%$ & $1.8 \%$ & $1.9 \%$ & 0.068 & 0.081 & 0.087 \\
\hline & $95 \% \mathrm{CI}$ & $3.2 \%$ & $3.5 \%$ & $3.8 \%$ & 0.134 & 0.159 & 0.171 \\
\hline
\end{tabular}

With these results, we are able to answer our research question. Comparing the GII and GIII gains shows that increasing immersion does result in significantly greater learning gains. There is a clear increase in retention for GIII compared to GII. Although these two groups had similar gains immediately after instruction, the classroom cohort lost almost all of their gains relative to their pre-instruction state. The GIII classes that visited the planetarium also showed a drop between the post-instruction and contemporaneous assessments, but this was smaller, resulting in a net positive Post-Pre gain. 
Figure 1. The gains (shown as effect sizes) between pairs of assessments (Cont-Pre, Post-Cont, Post-Pre) for Groups I, II, and III. Error bars are $95 \%$ confidence intervals.

\section{Gains Between Test Pairs}

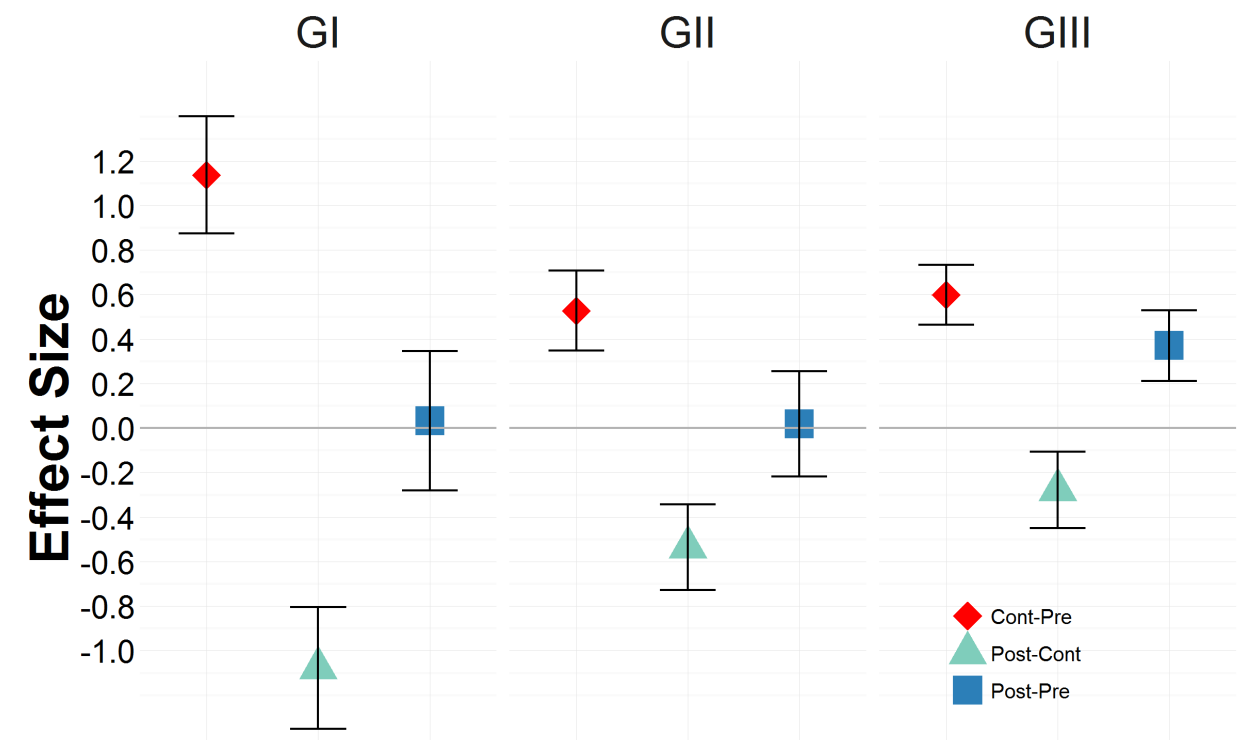

\section{Groups}

\section{DISCUSSION}

The performance discrepancy between GII and GIII suggests a real difference in student learning between those in the classroom versus those visiting the planetarium. The lecture outline, instructors, and visualization software were the same in the two treatment conditions, so next, we discuss how other factors-immersion, novelty, and peripheral imagery - could play a role in the difference in performance.

\section{Impact from Immersion}

Both FOV and display physical size are greater in the planetarium, resulting in deeper immersion than in the classroom. Screen size is also correlated with emotional reactions: larger pictures are rated as more arousing and receive more attention than smaller versions of the same imagery, irrespective of the content (Reeves, Lang, Kim, \& Tatar, 1999). Although arousal was not measured for any of our test subjects, if the dome is more arousing because it is more immersive, then arousal alone may explain the greater test performance by students in GIII versus those in GII. Although the narration provided by the lecturer is the same for the non-immersive GII classes, we do not expect these students to have their arousal or attention increased to the same extent as the students visiting the planetarium. Immersion in the planetarium may also minimize visual distractions. Wang and colleagues (2006) showed that realworld distractions can capture attention and decrease task performance of subjects working in an IVE. The FOV of a student in the planetarium is dominated by the hemispherical display, with the far periphery beyond the edge of the dome filled by the other members of the audience in their seats. As described earlier by Yu and colleagues (2015) the classrooms used in the experiment, the projected image subtends $11^{\circ}$ to $29^{\circ}$, depending on where the student is seated. A student in the classroom therefore experiences visual content that fills at most $5 \%$ of what a student in the planetarium sees. Although the lights were turned down in both environments, there is still more opportunity for a student to be distracted by the surroundings of the classroom or by other students since those environmental elements dominate the visual field more so than in the planetarium. 


\section{Novelty}

The novelty of GIII classes taking a field trip to the planetarium is a factor that has not been controlled for in this study. Previous research suggest that a multitude of novelty factors can inhibit learning by introducing unfamiliar elements that act as distractions (Slater, Ratcliff, \& Tatge, 2017). Decades prior to this study, Ridky (1975) argued that a "mystique effect" can impact student learning in the planetarium, but this can be mitigated if students first undergo an orientation session to familiarize them with the dome environment and its technology. Falk's (1983) review shows that students in both low and high novelty environments engage more in off-task behaviors, which is correlated with decreased learning. Again having students undergo an orientation session to introduce them to the novel environment made the greatest impact on learning and reduced off-task behaviors during the field trip. Finally the lack of familiarity with the field trip setting may only be one novelty factor that can affect student learning. Orion \& Hofstein (1994) identify a "novelty space" that also includes the unfamiliarity of the curriculum, as well as any unique aspects of the field trip program, such as learning materials, and teaching strategies. This latter effect should be minimal in our study since the curriculum and instructional strategies were the same for GII and GIII. Since GIII students performed better than those in GII, novelty to the planetarium appears not to be a negative contributing factor. There are two possible reasons for this. First, the curriculum module on Solar System moons was taught on the third visit to the dome. Any novelty effects that cause students to focus on their surroundings might have worn off by this point. A second possibility is that the experience in the dome is so immersive that the audience in the planetarium has no choice but to focus only on the visuals, even as they visually explore their environment. Thus the visual immersion may increase attention so much that it overcomes any learning impairment from the novel environment.

\section{Impact of Peripheral Imagery}

The greater GIII learning gains may ultimately have to do with the immersive elements that distinguish the fulldome planetarium display from the classroom flat screen. The wider FOV means that visual content is not concentrated only in the center forward direction, but can spill over to an audience member's peripheral vision. Visual content discussed in the lecture was placed in the center forward direction to ensure that it would be easily visible to everyone in the planetarium. However since the narrative journey mode was used in the presentations, the virtual camera would be aimed at the next object to be visited, and speed away from the current world. In the dome, the nearby moon or planet would move away and shift into the viewer's peripheral vision. Other nearby bodies would also shift in the visual field, but at different rates given their distances from the camera. Since moon orbital trajectories and identifying labels (floating near each object) were often actively rendered, these would also translate in directions and at speeds that depended on their relative positions to the virtual camera. For the GII classroom, the display is not immersive for even students seated close to it, since the area it subtends is at most $5 \%$ of what is visible in the planetarium. Instead of objects slipping into their peripheral vision, GII students see them clipped by the frame of the rectangular display and disappear as the camera flies past.

Experiments have shown that apparent motion in a subject's peripheral vision leads to vection, the sensation of motion even when that person is stationary; conversely when motion appears only in the center of the visual field, the subject feels that she is stationary while the objects in the scene are moving (Brandt, Dichgans, \& Koenig, 1973) through their peripheral vision. For the GII classes, the visual experience does not extend to the periphery so the students sense that they are stationary while the objects in the visualizations are moving. A larger screen size by itself may lead to more efficient egocentric spatial cognition strategies (Tan, Gergle, Scupelli, \& Pausch, 2006), in addition to leading to a greater sense of motion and excitement about content (Lombard, Reich, Grabe, Bracken, \& Ditton, 2000). Larger screens also interact with motion to impact subjective judgments of presence and vection (IJsselsteijn, Ridder, Freeman, Avons, \& Bouwhuis, 2001). Finally motion in video imagery has been linked to increased viewer arousal, and can capture and sustain attention (Detenber, Simons, \& Bennett, 1998). Given these prior results, we speculate that the large screen size of the fulldome planetarium may be interacting with the optical content flowing through the peripheral vision of audience members, to lead them to be more aroused and attentive to the presentation. 


\section{CONCLUSION}

We have constructed a lecture to accompany a "narrative journey" flight through an IVE, following a disciplinary discernment framework that uses astronomical visualizations to scaffold knowledge about moons of the Solar System. When comparing student performance in the classroom versus those who visited the planetarium, the latter show greater learning gains, even when the instructors, lecture content, and visuals are constant. Similar differences between the immersive and non-immersive treatments have been found in prior studies. When the same content is shown using different projection technologies, fulldome presentations have now been shown to be superior to flat classroom presentations (this work and Yu, Kahami, Sahami, \& Sessions, 2015), computer displays (Jacobson, 2010; Zimmerman, Spillane, Reiff, \& Sumners, 2014), and large-format cinema (Heimlich, Sickler, Yocco, \& Storksdieck., 2010). The current and past work lend support to the constructivist experiential learning model for 3D and IVEs (Fraser et al., 2012). We propose that visual immersion itself has benefits for learning by reducing cognitive load and increasing attention. Despite these tantalizing trends, the small number of studies prevents us from making any firm conclusions now about this particular medium for science communication. These results do point to the need for additional inquiry, especially investigations that focus on the specific ways in which visual immersion, and how quantifiable elements of that immersion (e.g., screen size, field-of-view) can impact audiences cognitively and affectively.

\section{ACKNOWLEDGMENTS}

This work was supported by the National Science Foundation under grants NSF ROLE 0529522 and DRL 0848945. We thank Pierre Chastenay, Urban Eriksson, and Julia Plummer for reviewing and commenting on an early draft of the paper. We acknowledge Chase Latta for software coding; Doug Howie, Greg Mancari, and Dan Neafus for logistical support; David Briggs and Tom Vogel for sorting, scanning, and editing interviews; Laurie Budke for transcriptions; and Katherine Honda for extensive library research.

\section{AUTHOR BIOGRAPHIES}

Ka Chun Yu is the Curator of Space Science at DMNS, which he joined in 2001 as part of a team tasked to create planetarium software to visualize the known universe. He continues to create new educational content and visualizations for displays like the digital dome and Science On a Sphere, and research the most effective ways of using this type of technology for education. He is one of the founders of the Worldviews Network, a group using immersive visuals to connect public audiences with global change issues. He currently serves on the International Planetarium Society's Science and Data Visualization Task Force, and IPS' Education Committee.

Kamran Sahami is Professor of Physics at MSUD. His research interests include non-linear systems, electro-optics and physics and astronomy education. He received his Ph.D. in Astrophysical, Planetary and Atmospheric Sciences from the University of Colorado in 2001, and also holds two Master of Science degrees in Astrophysics and Applied Physics. At MSUD, he has received the Faculty Senate Excellence in Teaching Award, served as the Interim Director of the Office of Sponsored Research and Programs, and served four terms as President of the Faculty Senate. In Spring 2014, he co-founded the MSUD Chapter of the AAUP and was elected its first President.

Grant Denn is Associate Professor of Physics at MSUD. He received a M.S. in Astronomy from Case Western Reserve University, and a Ph.D. in Physics from the University of Iowa. His research interests are in extragalactic radio astronomy, astronomy education, and music and perception.

Victoria Alten Sahami, M.S. is an astronomy instructor at MSUD. She has worked as a solar observer, done research in star formation, and built ultraviolet telescope rocket payloads rocket payloads. Currently, she prepares and leads total solar eclipse tours for Sirius Travel in addition to her teaching work.

Larry Sessions, a former planetarium director in Denver and Fort Worth, teaches astronomy at MSUD and the Community College of Aurora, blogs for EarthSky.org, and has a strong interest in promoting public awareness of astronomical events. He was formerly the managing editor at the Denver Museum of Natural History, as well as for 
the award-winning "Weather Guide" calendar from Accord Publishing. His articles have appeared in numerous publications including Sky \& Telescope, Astronomy and Rolling Stone.

\section{REFERENCES}

Abell, S., Martini, M., \& George, M. (2001). 'That's what scientists have to do': preservice elementary teachers' conceptions of the nature of science during a moon investigation. International Journal of Science Education, 23(11), 1095-1109.

American Association for the Advancement of Science AAAS (1986) Project 2061: Benchmarks for Science Literacy. Oxford University Press.

Angelov, A. N., Smieja, T., \& Styczynski, Z. (2007, September). Acceptance of 3D visualizations methods for learning and training in the area of electrical engineering. In International Conference on Engineering Education, Coimbra, Portugal.

Arsenault, D. (2005). Dark waters: Spotlight on immersion. In Game-On North America 2005 Conference Proceedings (pp. 5052).

Bailenson, J. N., Yee, N., Blascovich, J., Beall, A. C., Lundblad, N., \& Jin, M. (2008). The use of immersive virtual reality in the learning sciences: Digital transformations of teachers, students, and social context. The Journal of the Learning Sciences, 17(1), 102-141.

Barab, S. A., Hay, K. E., Barnett, M., \& Keating, T. (2000). Virtual Solar System Project: Building Understanding Through Model Building. Journal of Research in Science Teaching, 37(7), 719-756.

Barnea, N., \& Dori, Y. J. (1999). High-school chemistry students' performance and gender differences in a computerized molecular modeling learning environment. Journal of Science Education and Technology, 8(4), 257-271.

Barnett, M., \& Morran, J. (2002). Addressing children's alternative frameworks of the moon's phases and eclipses. International Journal of Science Education, 24(8), 859-879.

Baxter, J. (1989). Children's understanding of familiar astronomical events. International Journal of Science Education, 11(5), 502-513.

Bell, R. L., \& Trundle, K. C. (2008). The use of a computer simulation to promote scientific conceptions of moon phases. Journal of Research in Science Teaching, 45(3), 346-372.

Brandt, T., Dichgans, J., \& Koenig, E. (1973). Differential effects of central versus peripheral vision on egocentric and exocentric motion perception. Experimental Brain Research, 16(5), 476-491.

Bransford, J. D., Brown, A. L., \& Cocking, R. R. (2000). How people learn. Washington, DC: National Academy Press.

Brewer, W. F. (2008). Naive theories of observational astronomy: Review, analysis, and theoretical implications. International Handbook of Research on Conceptual Change, 155-204.

Callison, P. L., \& Wright, E. L. (1993). The Effect of Teaching Strategies Using Models on Preservice Elementary Teachers' Conceptions about Earth-Sun-Moon Relationships. Annual Meeting of the National Association for Research in Science Teaching. Atlanta, GA, April 15-18, 1993. 19p.

Chastenay, P. (2015). From Geocentrism to Allocentrism: Teaching the Phases of the Moon in a Digital Full-Dome Planetarium. Research in Science Education, 46(1), 43-37.

Comins, N. F. 2003. Heavenly Errors. Columbia University Press.

De Freitas, S., \& Neumann, T. (2009). The use of 'exploratory learning' for supporting immersive learning in virtual environments. Computers \& Education, 52(2), 343-352.

Dede, C., Salzman, M. C., Loftin, R. B., \& Sprague, D. (1999). Multisensory immersion as a modeling environment for learning complex scientific concepts. In Modeling and Simulation in Science and Mathematics Education (pp. 282-319). New York: Springer.

Dede, C. (2000). Emerging influences of information technology on school curriculum. Journal of Curriculum Studies, 32(2), 281303.

Detenber, B. H., Simons, R. F., \& Bennett Jr, G. G. (1998). Roll 'em!: The effects of picture motion on emotional responses. Journal of Broadcasting \& Electronic Media, 42(1), 113-127.

Durlach, N. I., \& Mavor, A. S. (1995). Virtual reality. Scientific and technological challenges. Naval Training Systems Center. Washington, DC: National Academy Press.

Eames, C. \& Eames, R. (1977). Powers of Ten film.

Emmart, C. (2005). The powers of ten with a steering wheel on the global visualization superhighway. The Planetarian, $34,19-26$.

Eriksson, U., Linder, C., Airey, J., \& Redfors, A. (2014a). Who needs 3D when the Universe is flat? Science Education, 98(3), 412-442.

Eriksson, U., Linder, C., Airey, J., \& Redfors, A. (2014b). Introducing the anatomy of disciplinary discernment: an example from astronomy. European Journal of Science and Mathematics Education, 2(3), 167-182.

Ermi, L., \& Mäyrä, F. (2005). Fundamental components of the gameplay experience: Analyzing immersion. Worlds in play: International Perspectives on Digital Games Research, 37, 2.

Falk, J. H. (1983). Field trips: A look at environmental effects on learning. Journal of Biological Education, 17(2), $137-142$.

Fiore, S. M., Harrison, G. W., Hughes, C. E., \& Rutström, E. E. (2009). Virtual experiments and environmental policy. Journal of 
Environmental Economics and Management, 57(1), 65-86.

Fraser, J., Heimlich, J. E., Jacobsen, J., Yocco, V., Sickler, J., Kisiel, J., Nucci, M., Jones, L.F., \& Stahl, J. (2012). Giant screen film and science learning in museums. Museum Management and Curatorship, 27(2), 179-195.

Heimlich, J. E., Sickler, J., Yocco, V., \& Storksdieck, M. (2010). Influence of immersion on visitor learning: Maya skies research report. Edgewater, MD: Institute for Learning Innovation.

IJsselsteijn, W. A., Ridder, H. D., Freeman, J., Avons, S. E., \& Bouwhuis, D. (2001). Effects of stereoscopic presentation, image motion, and screen size on subjective and objective corroborative measures of presence. Presence, 10(3), 298-311.

Jacobson, J. (2010, April). Digital dome versus desktop computer in a learning game for religious architecture. In Annual Meeting of the American Educational Research Association (AERA), Denver, CO.

Jones, B. L., Lynch, P. P., \& Reesink, C. (1987). Children's conceptions of the earth, sun and moon. International Journal of Science Education, 9(1), 43-53.

Kavanagh, C., Agan, L., \& Sneider, C. (2005). Learning about phases of the moon and eclipses: A guide for teachers and curriculum developers. Astronomy Education Review, 4(1), 19-52.

Keating, T., Barnett, M., Barab, S. A., \& Hay, K. E. (2002). The virtual solar system project: developing conceptual understanding of astronomical concepts through building three-dimensional computational models. Journal of Science Education and Technology, 11(3), 261-275.

Kolb, D.A. (1984) Experiential learning: experience as the source of learning and development. Englewood Cliffs, NJ: Prentice Hall.

Korakakis, G., Pavlatou, E. A., Palyvos, J. A., \& Spyrellis, N. (2009). 3D visualization types in multimedia applications for science learning: A case study for 8th grade students in Greece. Computers \& Education, 52(2), 390-401.

Lantz, E. (2011). Planetarium of the Future. Curator: The Museum Journal, 54(3), 293-312.

Livingstone, M., \& Hubel, D. (1988). Segregation of form, color, movement, and depth: anatomy, physiology, and perception. Science, 240(4853), 740-749.

Lochness Productions. (2016). Fulldome Theater Compendium. http://www.lochnessproductions.com/lfco/lfco.html, accessed 29 August 2016.

Lombard, M., Reich, R. D., Grabe, M. E., Bracken, C. C., \& Ditton, T. B. (2000). Presence and television: The Role of Screen Size. Human Communication Research, 26(1), 75-98.

Loomis, J. M., Blascovich, J. J., \& Beall, A. C. (1999). Immersive virtual environment technology as a basic research tool in psychology. Behavior Research Methods, Instruments, \& Computers, 31(4), 557-564.

Maxwell, S.E., \& Delaney, H.D. 2004. Designing Experiments and Analyzing Data: A Model Comparison Perspective, 2/e. Mahway, NJ: Lawrence Erlbaum.

National Research Council. 1995. National Science Education Standards. National Academies Press.

Ni, T., Bowman, D. A., \& Chen, J. (2006, June). Increased display size and resolution improve task performance in informationrich virtual environments. In Proceedings of Graphics Interface 2006 (pp. 139-146). Canadian Information Processing Society.

Northedge, A. (2002). Organizing excursions into specialist discourse communities: A sociocultural account of university teaching. Learning for Life in the 21st century: Sociocultural Perspectives on the Future of Education, 252-264.

Nunez, D. (2004, November). How is presence in non-immersive, non-realistic virtual environments possible?. In Proceedings of the 3rd International Conference on Computer Graphics, Virtual Reality, Visualisation and Interaction in Africa (pp. 83-86). ACM.

Orion, N., \& Hofstein, A. (1994). Factors that influence learning during a scientific field trip in a natural environment. Journal of Research in Science Teaching, 31(10), 1097-1119.

Partridge, B., \& Greenstein, G. (2003). Goals for “Astro 101”: Report on workshops for department leaders. Astronomy Education Review, 2(2), 46-89.

Plummer, J. D. (2014). Spatial thinking as the dimension of progress in an astronomy learning progression. Studies in Science Education, 50(1), 1-45.

Plummer, J. D., Kocareli, A., \& Slagle, C. (2014). Learning to explain astronomy across moving frames of reference: Exploring the role of classroom and planetarium-based instructional contexts. International Journal of Science Education, 36(7), 1083-1106.

Raja, D., Bowman, D., Lucas, J., \& North, C. (2004, May). Exploring the benefits of immersion in abstract information visualization. In Proceedings of the Immersive Projection Technology Workshop.

Reeves, B., Lang, A., Kim, E. Y., \& Tatar, D. (1999). The effects of screen size and message content on attention and arousal. Media Psychology, 1(1), 49-67.

Ridky, R. W. (1975). The mystique effect of the planetarium. School Science and Mathematics, 75(6), 505-508.

Schnall, S., Hedge, C., \& Weaver, R. (2012). The Immersive Virtual Environment of the digital fulldome: Considerations of relevant psychological processes. International Journal of Human-Computer Studies, 70(8), 561-575.

Schoon, K. J. (1988). Misconceptions in the earth and space sciences: A cross-age study. Doctoral dissertation, Loyola University of Chicago.

Shedd, B. (1989). Exploding the frame. http://www.sheddproductions.com/EXPLODING_THE_FRAME_Papers_\%26_Essays/ 
Entries/2008/10/27_Original_EXPLODING_THE_FRAME_article_-_Written_1989.html. Accessed 5 Jan 2016

Slater, M. (2003). A note on presence terminology. Presence $\bar{C}$ onnect, $\overline{3}(3), 1-\overline{5}$.

Slater, S. J. (2014). The Development and Validation Of The Test $\underline{\text { Of }}$ Astronomy STandards (TOAST). Journal of Astronomy \& Earth Sciences Education, 1(1), 1-22.

Slater, T. F., Ratcliff, M., \& Tatge, C. B. (2017). Research on Learning in the Planetarium. Netherlands: Springer.

Stahly, L. L., Krockover, G. H., \& Shepardson, D. P. (1999). Third grade students' ideas about the lunar phases. Journal of Research in Science Teaching, 36(2), 159-177.

Sumners, C. (2012). We Choose Space! Houston Museum of Natural Science (film).

Tan, D. S., Gergle, D., Scupelli, P., \& Pausch, R. (2006). Physically large displays improve performance on spatial tasks. $A C M$ Transactions on Computer-Human Interaction (TOCHI), 13(1), 71-99.

Toet, A., Jansen, S. E., \& Delleman, N. J. (2007). Effects of field-of-view restrictions on speed and accuracy of manoeuvring 1, 2 , 3. Perceptual and Motor Skills, 105(3f), 1245-1256.

Trundle, K. C., Atwood, R. K., \& Christopher, J. E. (2002). Preservice elementary teachers' conceptions of moon phases before and after instruction. Journal of Research in Science Teaching, 39(7), 633-658.

Trundle, K. C., Atwood, R. K., \& Christopher, J. E. (2007). A longitudinal study of conceptual change: Preservice elementary teachers' conceptions of moon phases. Journal of Research in Science Teaching, 44(2), 303-326.

Venturino, M., \& Wells, M. J. (1990, October). Head movements as a function of field-of-view size on a helmet-mounted display. In Proceedings of the Human Factors and Ergonomics Society Annual Meeting 34(19), 1572-1576. SAGE Publications.

Wandersee, J. H., Mintzes, J. J., \& Novak, J. D. (1994). Research on alternative conceptions in science. Handbook of research on science teaching and learning, 177, 210.

Wang, Y., Otitoju, K., Liu, T., Kim, S., \& Bowman, D. A. (2006, November). Evaluating the effects of real world distraction on user performance in virtual environments. In Proceedings of the ACM Symposium on Virtual Reality Software and Technology (pp. 19-26). ACM.

Welch, B. L. (1951). On the comparison of several mean values: an alternative approach. Biometrika, 38, 330-336.

Wong, A.J.A. (2009). Tales from the Maya Skies. Chabot Space \& Science Center (film).

Wyatt, R. (2005). Planetarium paradigm shift. The Planetarian, 34(3), 15-19.

Wyatt, R. (2014). Planetariums as 21 st Century Digital Dioramas. Informal Learning Review. 3-9.

Yoder, C. F. (1979). How tidal heating in Io drives the Galilean orbital resonance locks. Nature, 279, 767-770.

Yu, K. C. (2005). Digital full-domes: the future of virtual astronomy education. Planetarian, 34(3), 6-11.

Yu, K. C., Sahami, K., Sahami, V., \& Sessions, L. C. (2015). Using a digital planetarium for teaching seasons to undergraduates. Journal of Astronomy \& Earth Sciences Education, 2(1), 33-50.

Zimmerman, L., Spillane, S., Reiff, P., \& Sumners, C. (2014). Comparison of student learning about space in immersive and computer environments. Journal and Review of Astronomy Education and Outreach, 1(1), A5-A20. 


\section{APPENDIX A}

\section{Pre-Instruction}

Pr.1. A moon, in general, is most similar to which of the following?
A) live star
B) galaxy
C) terrestrial planet
D) comet
E) dead star

Pr.3. The number of moons in orbit around Jupiter is about
A) 0
B) $1-2$
C) 4 exactly
D) $18-20$
E) $60-70$

Pr.4. Planetary rings within our Solar System are found around
A) some gas giants
B) all gas giants
C) C) some terrestrial planets
D) all terrestrial planets
E) some planets: either terrestrial or gaseous

Pr.5. The total number of moons so far discovered within the Solar System is about
A) 1
B) 6
C) 15
D) 50
E) 150

Pr.7. Which type of planet that is likely to have many moons (greater than 10)?
A) Terrestrial planets
B) Jovian planets
C) Asteroids
D) Icy planets
E) No type of planet is more likely than any other type

\section{Contemporaneous}

Co.1. Triton is a moon around which planet?
A) Mars
B) Jupiter
C) Saturn
D) Neptune
E) Pluto

Co.4. Some gaps in the rings of Saturn are thought to be caused by
A) magnetospheric interactions
B) moons within the rings
C) cometary debris
D) volcanic activity
E) a sulfur ion torus 
Co.5. Moon systems are NOT found around which one of the following planets?
A) Venus
B) Mars
C) Jupiter
D) Pluto
E) All planets have moons

Co.6. What is the origin of the Earth's moon?
A) It is a captured asteroid
B) It condensed with the Earth at the birth of the Solar System
C) It is the result of a giant impact of another large body with the Earth
D) It is due to the Earth breaking into two parts
E) None of the above

Co.7. What is the most likely reason that a moon is spherically shaped?
A) tidal locking
B) atmospheric pressure
C) erosion via flowing liquids
D) self-gravity
E) numerous impacts

Co.8. Which of the following does NOT contribute to volcanic activity on Io?
A) high atmospheric pressure
B) tidal friction from Jupiter
C) elliptical orbit of Io
D) internal heat
E) orbital resonances with Europa

Co.13. The image below is of Saturn's moon Tethys. The surface feature in the box is most likely a
A) volcanic caldera
B) dry lake bed
C) giant impact crater
D) tectonic scarp
E) polar cap

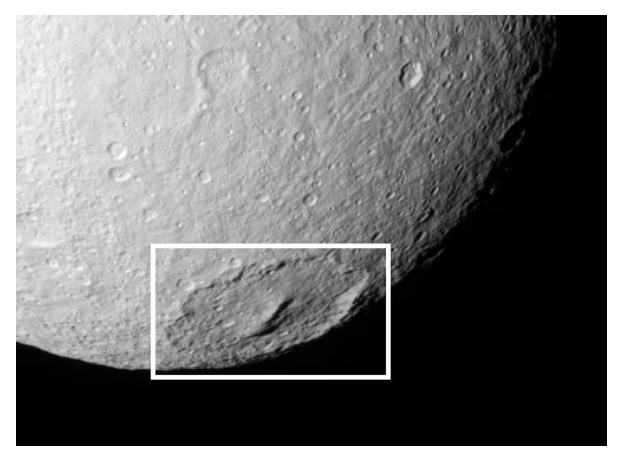

Co.15. The moon that has no obvious impact craters is
A) Miranda
B) Callisto
C) Phobos
D) Io
E) Titan 
Co.19. Kuiper Belt Objects are found

A) Between Mars and Jupiter

B) Within the Earth's orbit

C) Intermingled with the gas giants

D) Slightly outside of the gas giants

E) Hundreds to thousands of times farther from the Sun than Neptune

Co.25. The planet with only two small moons which are probably captured asteroids is
A) Venus
B) Mars
C) Earth
D) Mercury
E) Pluto

\section{Post-Instruction}

Po.2. Tidal friction is thought to cause which phenomenon?
A) Planetary rings
B) Synchronous rotation
C) Impact craters
D) Orbital resonances
E) Atmospheric outgassing

Po.3. The Earth's moon was caused by
A) A collision with a Mars-sized object
B) Condensation during the early solar system
C) Capture of a passing asteroid
D) Fission from the early Earth
E) None of the above

Po.4. Which of the following planets does not have rings?
A) Jupiter
B) Venus
C) Saturn
D) Uranus
E) Neptune

Po.5. The origin of a moon with a retrograde orbit is probably due to which of the following?
A) It is a captured asteroid, comet, or Kuiper Belt Object
B) It is the result of a giant impact
C) It is random
D) It was formed with the planet
E) No moons have retrograde orbits 


\section{APPENDIX B}

Table 1 lists the means $(M)$ for Solar System moons-related questions for the classes in the three experimental groups, along with the standard error $(S E)$, and $95 \%$ confidence interval $(C I)$. The numbers $(n)$ represent only those students who were present for a particular weekly assessment, and therefore, whose scores contributed to the final analysis. One-way ANOVA tests with a Welch correction for non-homogeneity of variances (Welch, 1951) show that the preinstruction average scores did not differ between GI, GII, and GIII at the $95 \%$ confidence level $\left(F_{(2,282.2)}=0.585 ; p<\right.$ $0.5577)$. By contrast, the contemporaneous with instruction $\left(F_{(2,290.2)}=9.34 ; p<0.001\right)$ and post-instruction scores $\left(F_{(2,267)}=8.82 ; p<0.001\right)$ all were significantly different between the three Groups. A Games-Howell test for posthoc comparison for unequal sample sizes and unequal variances on the post-instruction mean scores show that the GI and GII means are not significantly different $(t=0.058, d f=229.0, p=0.998)$, while GIII is significantly different from the other two (GI-GIII: $t=3.38, d f=192.0, p=0.003$; GII-GIII: $t=3.55, d f=394.3, p=0.001$ )

Table 2 shows mean longitudinal gains $g$ (determined by calculating the gain for each individual student, before taking the average) between the Cont-Pre, Post-Cont, and Post-Pre results. Gains are reported in percentages and effect sizes $(E S)$. A one-way ANOVA test using Welch's correction shows significant differences between the gains when comparing pairs of tests in the three experimental Groups: $F_{(2,235.1)}=12.08(p<0.0001)$ for Post-Cont, $F_{(2,234.3)}=$ $7.89(p<0.001)$ for Cont-Pre, and $F_{(2,208.4)}=3.86(p=0.02)$ for Post-Pre. However an ANOVA test does not indicate which of the three experimental groups differ from each other, so a follow-up post-hoc test is needed. Instead of Tukey, we choose Games-Howell which is valid for distributions with both unequal sample sizes and unequal variances (Maxwell \& Delaney, 2004; p. 212). For the Post-Cont gains, two of the group comparisons have significantly different means (GI-GII: $t=3.79, d f=179.6, p<0.001$; GI-GIII: $t=3.61, d f=145.3, p=0.001$ ), but GII-GIII does not $(t=1.97, d f=406.3, p=0.12)$. For the Cont-Pre gains, GI-GII $(t=3.79, d f=179.6, p<$ $0.001)$ and GI-GIII $(t=3.61, d f=145.3, p=0.001)$ have significantly different means, while GII-GIII does not $(t=0.62, d f=350.8, p=0.81)$. For the Post-Pre gains, the means are significantly different from each other only when comparing GII:GIII $(t=2.44, d f=293.6, p=0.04)$, but not for GI-GII $(t=0.067, d f=175.5, p=0.998)$ or for GI-GIII $(t=1.91, d f=129.3, p=0.14)$. 


\section{NOTES}

